\title{
An Action Research on Open Knowledge and Technology Transfer
}

\author{
Isabel Ramos ${ }^{1}$, Margarida Cardoso ${ }^{1}$, João Vidal Carvalho ${ }^{1}$, and José Ismael Graça ${ }^{2}$ \\ ${ }^{1}$ University of Minho, Portugal \\ ${ }^{2}$ Município de Vila Verde, Portugal
}

\begin{abstract}
R\&D has always been considered a strategic asset of companies. Traditionally, companies that have their own R\&D function are better prepared to compete in the globalized economy because they are able to produce the knowledge and technology required to advance products and services. SMEs also need to become highly innovative and competitive in order to be successful. Nevertheless, their ability to have an internal R\&D function that effectively meets their innovation needs is usually very weak. Open innovation provides access to a vast amount of new ideas and technologies at lower costs than closed innovation. This paper presents an action research study being carried out at University of Minho to develop a business model and technology platform for an innovation brokering service connecting ideas and technologies being developed at Universities with the specific innovation needs of SMEs. The expected contributions of the study include the empirical investigation of the effectiveness and risks of crowdsourcing innovation when applied in the socioeconomic context of a European developing country where SMEs represent $99,6 \%$ of the businesses.
\end{abstract}

\section{Introduction}

R\&D has always been considered a strategic asset of companies. Traditionally, companies that have their own R\&D function are better prepared to compete in the globalized economy because they are able to produce the knowledge and technology required to advance products and services.

However, large companies are the best equipped to invest in the resources required to keep a R\&D function that meets their innovation needs. In addition, a number of factors converge to make it difficult, even for large companies, to internally produce all the knowledge and technologies they need to innovate: the instability of the world economy, the fast pace of scientific knowledge being produced in all disciplines, the complexity of the multi-disciplinary knowledge required to support innovation, the rapid decrease of products and processes life cycles. Even in an economy that is no longer growing or is growing at a much slower rate than before, the pressure to innovate and to offer valuable products and services is strategic; due to decreasing investment and purchasing power, investors and consumers will probably become more selective and demanding. 
SMEs also need to become highly innovative and competitive in order to be successful. Nevertheless, their ability to have an internal R\&D function that effectively meets their innovation needs is usually very weak. Often, these companies are dependent on their ability to rapidly detect and take advantage of opportunity windows. For this to happen, SMEs may require competencies and technologies that they do not possess internally.

In fact, SMEs have always been forced to use others' technologies due to their sparse internal resources which are devoted to innovation. Competitive advantage can be achieved if technology and ideas are available. Brokers can help SMEs to access the market of ideas and solutions, structured knowledge repositories and networking along the value chain.

Open Innovation (Chesbrough, 2003a) is a strategy that is emerging as highly promising in an unstable and uncertain world, where a global workforce of knowledge workers is eagerly seeking for work opportunities perceived as enriching and empowering. This strategy acknowledges the emergence of a market for ideas and emerging technologies supported by vast global offerings of complex knowledge and skills. In this paper we call this strategy 'crowdsourcing innovation'.

In a networked environment, where relations need to be established in a near realtime basis with a large base of potential customers, using the service of a crowdsourcing innovation broker can be the solution to counteract SME's scarce means and scalability difficulties.

Crowdsourcing innovation provides access to a vast amount of new ideas and technologies at lower costs than closed innovation. However, this innovation strategy, or any other open innovation strategy, should not completely replace internal R\&D function. Internal R\&D is still necessary to ensure the learning required for evaluating the relevance of external knowledge and technologies and to support the organizational and business changes that must be implemented to integrate them.

In the European Union, $99 \%$ of businesses are SMEs and they provide two-thirds of all private sector jobs (http://ec.europa.eu/enterprise/entrepreneurship/facts_figures.htm).

Given the key role played by SMEs in the European economy, it will come as no surprise if the open innovation strategy finds many adepts in EU. European managers are increasingly becoming interested in open innovation as a strategy to improve and extend the innovation capability of their companies. Nevertheless, this strategy is not yet fully developed as a new management practice and there are still many challenges to be overcome in the appropriate implementation of it which require further scientific research.

This paper presents an action research study being carried out at the University of Minho that aims at developing a business model and technology platform for an crowdsourcing innovation brokering service connecting ideas and technologies being developed at Universities with the specific needs of SMEs.

The paper starts by presenting the foundations of the planned research. The concepts of community and network are presented, followed by a brief discussion on their relevance in the context of crowdsourcing innovation.

The rationale underlying the study being carried out at the University of Minho is presented. The research planned for the next three years is explained and justified. Finally, the expected contributions, both for theory and practice, are put forward. 


\section{Open Innovation: Concept and Communities}

Chesbrough and Schwartz (2007) define open innovation as the "(..) use of purposive inflows and outflows of knowledge to accelerate internal innovation, and expand the markets for external use of innovation, respectively", (Chesbrough and Schwartz, 2007: 55). More specifically, firms can include the following archetypes of core processes, when adhering to an open innovation process: outside-in or inside-out processes or a coupled one (Gassmann and Enkel, 2005).

The open innovation paradigm implies co-developmental partnerships, developing a mutual working relationship (versus the traditional defensive business strategy), and using external sources of knowledge. These partnerships might look for the delivery of a new product, technology, or service, to reduce R\&D expenses (Chesbrough and Schwartz, 2007), to expand the innovation output and its impact, and even to open new markets which are otherwise inaccessible. Recent studies on innovation have stressed the growing relevance of external sources of knowledge and creativity (Perkmann and Walsh, 2007). These studies have showed that more than trusting their R\&D labs, organizations should adopt the open innovation strategy (Chesbrough and Crowther, 2006). This means that innovation can be considered the result of knowledge networks connecting several organizations instead of a function within one organization (Coombs et al. 2003; Powell et al. 1996). In the same line of reasoning, the concept of interactive innovation was established to understand the non-linear, iterative and multi-agent nature of the innovation processes (Kline,1985; Lundvall, 1988; Von Hippel, 1988).

Collaboration with suppliers is already an important part of the innovation strategy of large organizations (Törrö, 2007). Simultaneously, the traditional outsourcing of innovation, in which the full responsibility for part of the innovation process is transferred to another organization, is growing in popularity. The trend is, however, to form extensive networks in order to reach external competencies.

The challenge is now to diversify the innovation sources by identifying and attracting individuals and organizations worldwide in order to gather ideas and solutions and to, eventually, choose the ones that can complement the internal innovation process (Bowonder et al., 2005; Moitra and Krishnamoorthy, 2004; Perrons and Platts, 2004; Fowles and Clark, 2005; Quinn, 2000; Chesbrough, 2003a).

Laursen and Salter (2006) have explored the relationship between the opening of the organization to its external environment and its innovation performance. They have concluded that organizations that are open to external sources of innovation, or that use external inquiry channels, have a higher level of innovation performance. By studying British industrial companies, the authors showed that these companies adopted systematic strategies to search various channels and in doing so they were able to get ideas and resources that enabled them to identify and explore opportunities for innovation. This study follows the work of Cohen and Leventhal (1990), who argue that the ability to explore external knowledge is a key element of the innovation performance.

The open innovation model lays emphasis in the knowledge flow through the organization boundaries (1) to enable the accelerated development of internal innovations (i.e., supported by the licensing of technologies developed by others), and (2) to expand the use of technologies internally developed that could become underused. 
The main challenge in adopting the open innovation model is in finding the right people and in fostering the collaborative work with the aim of integrating scientific discoveries in an innovative way (Chesbrough et al., 2006).

\subsection{Collaboration in the Context of Open Innovation}

Collaborative networks are crucial for the overall open innovation concept. Some studies show their importance in the improvement of companies' innovation performance. Nieto and Santamaria (2007) research shows how different types of collaborative networks contribute to the upgrading and innovation of industrial products. Using longitudinal research data about Spanish industrial companies, results show that a collaborative network is of crucial importance to reach a higher degree of innovation in specific products. Collaboration with suppliers, customers and other firms has a positive impact in innovation, while the collaboration with competitors has a negative impact. This study also offers evidence that the main positive impact on innovation comes from collaborative networks holding different types of participants.

Perkmann and Walsh (2007) explore characteristics of collaborative relationships between universities and industry through an open innovation perspective. Authors present a model, distinguishing university-industry partnerships from other mechanisms such as technology transfer or just human mobility processes.

Crowdsourcing innovation, one of the several open innovation strategies, brings in the need for collaboration within and between two main groups: the seekers, individuals and organizations seeking intellectual assets; and the solvers, individuals and organizations willing to produce those assets. Whether these groups should be called knowledge communities or networks is still under discussion and in need of further research.

Though seen in conjunction many times, the concepts of community and network can be safely parted. Dal Fiore refers to the difference between the tension that occurs with-in a community, towards homogenization and conservation, as something that makes it a space of belonging; and the network implying a tension towards differentiation, creative communication and also a space for competing (Dal Fiore, 2007) or instead, being just a more adequate notion to larger scale social realities (Mitchell, 1974).

When analyzing internet commercial sites and associated knowledge built-up processes, Loong (2008) calls attention to the fact that the community concept is somewhat fluid but nevertheless contains significant association to the object of the author's analysis, increasing value through informal knowledge creation. The author says community stands for "local social arrangements beyond the private sphere of the home and family" (Loong, 2008, p.182) and this shows through the development of relationships in online communities. Authors like Gee-Woo et al. (2005) call our attention to the fact that motivational factors are important, referring to individual benefits, reciprocal and community interests' defense behaviors, and organizational benefits. The authors suggest at its importance to nurture knowledge sharing behaviors and also sustain active communities. As Magalhães says, "Through the sharing of knowledge, the commitment of the group's members is strengthened and as new knowledge is produced the group gradually develops its own identity." (Magalhães, 2004, p.95). On the 
other hand, community can be considered a distributed communication system or systems, considering distributed communities which account for dispersion and individualization (nodes), and also using the Internet as an enabler tool (Gochenour, 2006).

The network concept might have entered social sciences through urban complex grounds, opposing the previous notion of community inherent to anthropological original studies in small-scale societies (Mitchell, 1974). Attention is called to the fact that usually authors either choose a morphological approach or an interactional one. Morphology can include several aspects, considering connectedness, density, anchorage, accessibility. Interaction includes content, directedness, durability, intensity and frequency. Sometimes, too, authors mingle criteria to obtain specific and more expressive operational constructs. Mitchell gives particular attention to content, which includes communication contents, transaction (or exchange) and normative content (relational).

A social network is something that affects the flow and quality of information (Granovetter, 2005; Ahonen and Lietsala, 2007; Perkmann and Walsh, 2007), that means also the need for coordination mechanisms (Gassmann and Enkel, 2005). Sources of reward but also punishment (Granovetter, 2005; Ahonen and Lietsala, 2007), networks are based on social capital (Bourdieu, 2001; Lin, 2001), establishing layers of intellectual capital (Törrö, 2007) - somehow a parallel with the sociotechnical model of Bressand and Distler (1995), which includes a layer one, for infrastructure (physical support for communication); a layer two, for infostructure, formal symbolic communication rules; and finally a layer three, for infoculture, the background taken-for-granted knowledge (Lehaney et al., 2004). These networks integrate ideas, and one must consider that the acceptance of an idea is part of its comprehension (DiMaggio, 2007), and so being the comprehension of related knowledge and technology. Trust is an important factor (Granovet-ter, 2005; Ahonen and Lietsala, 2007), and most of all a network is embedded in an interconnection of networks. This means that an additional layer is built in the organization.

Gassmann and Enkel (2005) make an in-depth study of 230 networks to determine their management mechanisms: through this study they come to know that firms gain if they integrate networks' work in their R\&D, because they are enabled to capture knowledge from the outside of the organization. The network might also facilitate a company's transition from a rigid structure to a flexible one (see Gass-mann and Enkel (2005), for a comprehensive enunciation of a network's structural elements). Networks can also be defined as social processes or configurations, as Perkmann and Walsh (2007) state.

\subsection{Open Innovation Brokering}

There is a growing interest in innovation brokering services (Arora et al., 2002; Chesbrough and Crowther, 2006). The number of companies that mediate the intellectual capital transactions and provide their clients with a new approach to implement inbound and outbound crowdsourcing innovation is growing.

Organizations must integrate a set of specific competencies and capabilities to efficiently manage ideas and suggestions. Brokering companies (brokers) have emerged to deal with a growing demand for creativity and solutions: the new market of ideas. 
Brokers require a strong presence in the Web through intelligent platforms that facilitate the innovation management and implement security mechanisms that ensure the confidentiality of exchanged information and the anonymity of seekers and solvers. These companies act as intermediaries that make available a set of services supporting innovation for their company clients (seekers) (Chesbrough, 2003). These platforms are part of the Web 2.0 and are integrating concepts and technologies of the so called Web 3.0 (Lassila and Hendler, 2007).

Companies as Innocentive, yet2.com, Nine Sigma, IdeaWicket, IdeaConnection and YourEncore are well known examples of crowdsourcing innovation brokers. They help in creating a global market for scientific knowledge, where everyone can contribute with her/his ideas and own developed technology. These brokers have been studied and are key players in the crowdsourcing innovation brokering for medium and large companies. As far as the authors know, no such studies have been performed for brokers offering a specialized service for micro and small companies and cultural issues affecting open innovation brokering have not yet been studied.

\section{Crowdsourcing Innovation at the University: An Action-Research Project}

Portuguese SMEs are dominant in the Portuguese business-related structure, representing $99,6 \%$ of the businesses and being responsible for $75,2 \%$ of private jobs and generating more than $1 / 2$ of the national wealth (IAPMEI Report for 2008 at http:// www.iapmei.pt/resources/download/sobre_pme_2008.pdf). Micro and small firms assume a key role in Portuguese economy, representing 97,3\% of all firms, offering $55,2 \%$ of the private jobs and $1 / 3$ of the national turnover.

The stronger economic sectors in which SMEs operate are commerce and services (including tourism). Other important sectors are construction, manufacturing industry, and energy.

Traditionally, SMEs are located in North of Portugal and Lisbon (2/3), therefore $70 \%$ of the private jobs are in these two regions. These SMEs are responsible for more than $70 \%$ of the national turnover. The remaining $1 / 3$ of the firms are located in the Center, South, Madeira and Azores.

The University of Minho is located in North of Portugal, in the Minho region. The University is renowned for the quality of its teaching and research. It holds strong links with the regional and national academic and business communities, consolidated through many teaching and project collaborations and multi-disciplinary projects. It has also a significant experience in international collaborations, both with universities and companies.

University of Minho has a student population of 16,000, 1,900 of them being postgraduate students. The University has 1,200 teaching staff and 600 administrative and technical staff.

Open Innovation is now capturing the attention of European managers. In Portugal, medium and large companies have already gathered important experience by collaborating with Universities in research projects that integrate the participation of $\mathrm{PhD}$ students. Some events supported by companies operating in the IT sector have 
launched events and challenges to post-graduate students in order to stimulate creativity and entrepreneurship. However, at present, there aren't brokering initiatives linking SMEs (seekers) to knowledge and technologies being developed in Universities by post-graduate students whose work is integrated in R\&D academic projects.

Most Portuguese SMEs, especially micro and small companies cannot afford the costs of accessing the brokering services provided by Innocentive and other international brokers. Since many of the Portuguese Universities are public universities, it seems highly desirable that public budget that is made available to Universities should end up generating intellectual assets benefiting SMEs, the main producers of national wealth. The remainder of this paper describes a study designed to investigate the process of implementing an crowdsourcing innovation initiative along the lines just described, eliciting the practices, dynamics and risks of a broker operating in a developing country and focusing the socio-economic constraints affecting SMEs.

The study being carried out at the Department of Information Systems at University of Minho has as its main goals:

a. To define a contextualized business model for a Crowdsourcing Innovation Broker focused on facilitating SME's access to ideas and technologies being developed at Universities, and in providing consulting services to support their integration in the SME's business processes.

b. To develop a web platform prototype to support the broker's processes, community's interactions and access to knowledge assets, and to support the collective memory functions such as re-construction of past experience, identity reformulations, and spontaneous formation of free associations.

To achieve these goals, a research program was defined for the next three years, which started in 2008 with the integrated research work of three PhD students in the areas of (1) online communities and networks, (2) crowdsourcing innovation and supporting web platforms, (3) organizational memory.

The research method used to guide the study is action research that "is an interventionist approach to the acquisition of scientific knowledge" (Baskerville and WoodHarper, 1996), that can be applied according the assumptions of post-positivist or interpretivist paradigms (Elden and Chisholm, 1993). Action research can also be considered as a kind of transformative methodology (Gobo, 2008), meaning a way of interfering with the state of the object, including manipulation of some of its states. Together with action research, Gobo presents a set of qualitative methodologies for social research such as interviews, surveys (qualitative), ethnography, documentary and other.

Action research can be compared, at least in terms of impact over the subject, to the ethnographic approach and case study. While the case study method allows a set of steps to gather and analyze information (Yin, 2003), the ethnographic method means immersion in the field; it requires observation skills and records to apply the method and offer testimonials of the context (Flick, 2005).

The choice of action research is based on the fact that it implies a certain degree of experimentation and production of technology which is scientifically grounded. The ethnographic methods don't imply this immediately, because of their immersive nature and because they do not include the experimental component. 
Therefore, the study described in this paper applies the action research method according to the interpretivist assumptions about what constitutes 'valid' research and which research methods and techniques are appropriate.

The Fig. 1 shows the action research cycle, adapted to the study of the OI brokering service to SMEs.

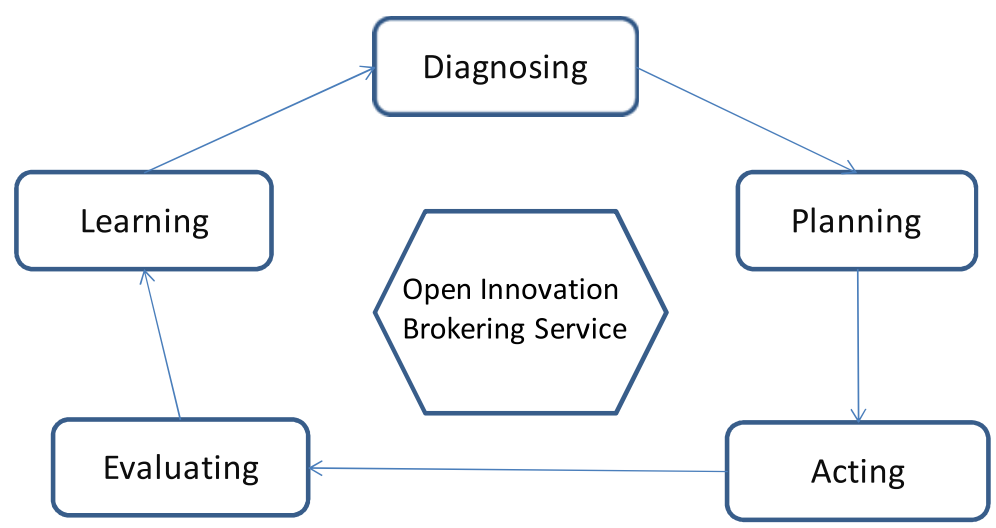

Fig. 1. The Action-Research Cycle applied for the study

The focus of the research is the definition and implementation of a brokering service for expanding the innovation capabilities of SMEs by employing the creativity and motivation of post-graduate students at public Universities to produce intellectual assets that can leverage the competitiveness and internationalization of Portuguese SMEs.

Diagnosing corresponds to understanding of the innovation benefits and constraints of the service. It also seeks to define the business and organizational models. Planning corresponds to defining the actions required to implement the defined models. The produced plan defines the target for change and the approach to change.

Acting corresponds to implementing the plan, requiring changes to be made. In the evaluating stage, the success of the actions carried out is evaluated against the expected outcomes, previously defined upon existing scientific studies on open innovation brokering services.

The experience gained within each action research cycle is consolidated in the learning stage, which is then used to start a new cycle that begins with a new "Diagnosing" activity.

Figure 2 shows the architecture of the service that we expect to develop by the end of our study.

We have planned three action-research cycles in the next three years. In each cycle, the service will be improved and deployed. The first cycle started in July 2008 with the first implementation of the brokering service. This implementation integrates small communities of seekers and solvers, but with strong ties with the service providers, the master programs management board. The main challenges of this initial stage are to ensure the quality of the service and its reputation beyond the present 


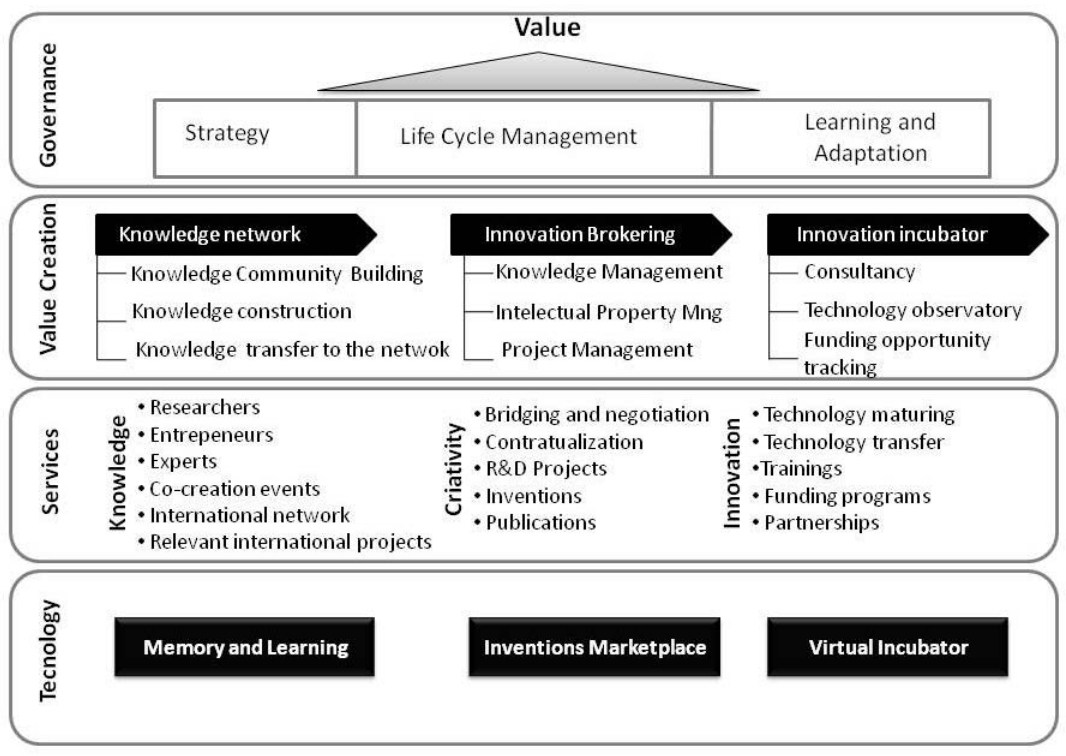

Fig. 2. The Architecture of the Service

communities involved in order to widen both communities. In preparation for the next action-research cycle, efforts are being made (1) to develop information services that can support creativity and project execution, and (2) to make available a knowledge network of national and international specialists in various scientific areas, willing to collaborate with the service to provide contents and knowledge transfer activities.

\subsection{Research Design: Research Questions and a Plan for Action}

At present, building the University crowdsourcing innovation's community (seekers and solvers) relies on a personal interaction and face-to-face communication, researchers' network and credibility, and the national reputation of its Information Systems master courses. SMEs are complying due to multiple and probably subjective factors. Nevertheless, as Foth (2006) stresses, "the majority of communication and interaction facilitated by global networks can be categorized as social and informal and takes place within the geographical vicinity of actors." (Foth, 2006, p.207).

The research questions that will be answered in the next three years are:

a. What are the key success factors of a crowdsourcing innovation brokering service focused on the specific innovation needs of SMEs?

b. What are the specific characteristics of the business model that ensures the sustainability of the service? What risks must be considered?

c. What are the functional components of a web platform that adequately supports the service?

d. What practices and technologies should be put in place to ensure a collective memory that adequately fosters creativity and knowledge coconstruction among the members of both solver and seeker communities? 
Several learning cycles will be deployed. In each cycle, the brokering service will be improved based on the experience gained in the several phases of the cycle and based on theoretical insights developed in previous studies performed by other researchers.

\subsection{Present Stage of the Research Work}

At present, our research is at the stage "Evaluating" of the first cycle of the action research (see Fig. 1). We have started by clarifying the benefits and risks of the brokering service. This activity lead to the understanding that the service has a strong potential for success but its hosting in one of the University's interface unit should be only the initial stage of a more ambitious service. The final service, the result of several cycles of action research, should be provided by a spin-off of the University that could aggregate several Portuguese public institutions of Higher Education and support the co-creation of intellectual assets, first with Portuguese SMEs and later with SMEs of Portuguese speaking countries.

To guide the first cycle of action-research, a mission, goals and strategy were defined for a brokering service provided by the Information Systems Department, the department of the researchers. The opportunity emerged from the fact that one of the researchers, and co-author of the paper, is the Head of the Information Systems Master programs. This fact facilitates the access to an initial community of solvers (the master students doing the dissertation) and a community of seekers (the companies that usually employ master students after they complete the program). In addition, Information Systems PhD students are also encouraged to solve innovation problems made available by the seeker companies.

Having identified both communities and having the process of Dissertation as the underlying structure for the service, plans were made to implement this first instantiation of the brokering service. The main concern was to define the steps to ensure reputation that will then support the success of next action research cycles in which more and more complex instantiations of the service will be deployed and studied. This reputation involves the delivery of valuable results to the SMEs and ensuring that students develop technical and soft skills required to their professional success. It also requires the adequate support to project management and the guarantee that the seeker and the solver commitments (financial prizes, available resources, effort, and others), defined at the initial stage of the project, are fulfilled.

The first activity taken was to host two creativity facilitating events called Knowledge Safari. In these events, companies were invited to share their innovation problems and goals with the researchers of the Information System Department. From these events, involving a modest number of 10 companies and 12 researchers representing all relevant research areas in the department, resulted 44 ideas for Dissertation projects. Most of these ideas were made available to master students.

While the paper is being written, students are choosing their dissertation process and defining their project's plan. We are evaluating the results we are obtaining and are already able to draw some insights:

a. Given the initial phase of the initiative, the strong ties that the department holds with the participating companies as seekers were central to the success of the creativity fostering events. Participants in the events, both 
managers and researchers, positively responded to the sense of community and were motivated to share ideas and problems.

b. The established reputation of the master programs was pivotal for the establishment of the initial reputation of the service.

c. Some companies that collaborate with the Department in other educational programs, and that usually employ the graduates and post-graduates, decided to wait and watch before getting involved with the service.

d. Even with this simple instantiation of the brokering service, it is clear that the huge amount of effort is required to manage interactions with both communities, to negotiate the different interests, to expand the communities, to manage the projects being carried out, and to facilitate the access to information and knowledge.

e. In order to involve other departments of the University, with the aim of widening the community of solvers and also of encouraging multidisciplinary projects, the service must be hosted by an interface unit of the University. Being delivered by the Department of Information Systems places the service in the Information Systems and Technologies field and implies a secondary role for the other departments.

f. Based on the insight in e), it is also evident that to leverage the service to a national and international level it cannot be hosted by the University of Minho but by an independent broker. This conclusion reinforces the initial assumption that in one of the next cycles, the creation of a University's spin-off company is required to enlarge its scope and quality.

These insights will be refined and extended in the near future. They will provide the ground for understanding the implementation of a crowdsourcing innovation brokering service in the academic context of a developing country where SMEs are responsible for the major part of its national turnover.

In order to prepare for the next action research cycle, a proposal for a funded project is being prepared to apply for the funding required to implement a service hosted by one of the interface units the University. This will attempt to define a business model that ensures the sustainability of the service as well as the required autonomy and flexibility needed to improve the service quality and widen its reach.

\section{Conclusions}

The paper presents an action research study being carried out at the University of Minho to develop a business model and the supporting web 3.0 platform for a brokering service focused on the innovation needs of SMEs.

The study is planned for three years and will integrate several action research cycles aimed at delivering increasingly sophisticated versions of the service.

The expected contributions of the study include the empirical investigation of the effectiveness and risks of crowdsourcing innovation strategy when applied in the socio-economic context of a European developing country where SMEs represent $99.6 \%$ of the businesses. 
The study will result in the definition of a functional architecture of a web platform that takes advantage of the Web 3.0 technologies and supports the specific requirements of an innovation brokering service for SMEs, followed by the development of a prototype that implements that architecture.

Practitioners will benefit from the insights produced which will be integrated in a methodology for guiding the definition and implementation of a brokering service focused on the specific innovation needs of SME and in the architectural aspects of a web platform that adequately supports the service.

\section{References}

Ahonen, M., Lietsala, K.: Managing service ideas and suggestions - information systems in innovation brokering. In: Innovation in Services. Conference Proceedings. Tekes, Berkeley (2007)

Arora, A., Fosfuri, A., Gambardella, A.: Markets for Technology. The Economics of Innovation and Corporate Strategy. MIT Press, Cambridge (2002)

Baskerville, R.L., Wood-Harper, A.T.: A Critical Perspective on Action Research as a Method for Information Systems Research. Journal of Information Technology (11), 235-246 (1996)

Bourdieu, P.: Razões práticas: Sobre a teoria da acção. Celta Editora, Lisboa (2001)

Bowonder, B., Racherla, J.K., Mastakar, N.V., Krishan, S.: R\&D spending patterns of global firms. Res. Technol. Manag. 48(5), 51-59 (2005)

Bressand, A., Distler, C.: La planète relationelle. Flamarion, Paris (1995)

Chesbrough, H.: The era of open innovation. MIT Sloan. Manag. Rev. 44(3), 35-41 (2003)

Chesbrough, H.: Open innovation: The New Imperative for Creating and Profiting from Technology. Harvard Business School Press, Boston (2003a)

Chesbrough, H., Crowther, A.K.: Beyond high tech: early adopters of open innovation in other industries. R\&D Manag. 36(4), 229-236 (2006)

Chesbrough, H., Schwartz, K.: Innovating business models with co-development partner-ships. Res. Technol. Manag. 50(1), 55-59 (2007)

Chesbrough, H., Vanhaverbeke, W., West, J.: Open innovation: researching a new paradigm. Oxford University Press, Oxford (2006)

Cohen, W.M., Levinthal, D.A.: Absorptive capacity: A new perspective on learning and innovation. Adm. Sci. Q 35(1), 128-152 (1990)

Coombs, R., Harvey, M., Tether, B.S.: Analysing distributed processes of provision and innovation. Ind. Corp. Chang. 12, 1125-1155 (2003)

DiMaggio, P.: Culture and congnition. Annual Review of Sociology 23, 263-287 (1997)

Elden, M., Chisholm, R.F.: Emerging Varieties of Action Research: Introduction to the Special Issue. Human Relations 46(2), 121-142 (1993)

dal Fiore, F.: Communities versus networks: the implications on innovations of social change. American Behavioural Scientist 50, 857-866 (2007)

Flick, U.: Métodos qualitativos na investigação científica, Lisboa, Monitor (2005)

Foth, M.: Network action research. Action Research 4(2), 205-226 (2006), http: / /arj . sagepub.com/cgi/reprint/4/2/205 (15.10.2008)

Fowles, S., Clark, W.: Innovation networks: good ideas from everywhere in the world. Strat. Leader 33(4), 46-50 (2005)

Gassmann, O., Enkel, E.: Management mechanisms of network layers in MNE. Presented at the European Academy of Management (EURAM) 2005 Conference, Munich (2005),

http: / /www. scientificcommons . org/836 (accessed April 26, 2008) 
Gee-Woo, B., Zmud, R.W., Young-Gul, K., Jae-Nam, L.: Behavioural intention formation in knowledge sharing: examining the roles of extrinsic motivators, social-psychological forces and organizational climate. MIS Quarterly 29(1), 87-111 (2005)

Gobo, G.: Doing ethnography. Sage, Los Angeles (2008)

Granovetter, M.: The impact of social structure on economic outcomes. Journal of Economic Perspectives 19(1), 33-50 (2005),

http: / /www.stanford.edu/dept/soc/people/mgranovetter/ (21-09-2008)

Kline, S.J.: Innovation is not a linear process. Res. Manag. 28(4), 36-45 (1985)

Lassila, O., Hendler, J.: Embracing Web 3.0. IEEE Internet Computing 11(3), 90-93 (2007)

Laursen, K., Salter, A.: Open for innovation: The role of openness in explaining innovation performance among U.K. manufacturing firms. Strat. Manag. J. 27(2), 131-150 (2006)

Lehaney, B., Clarke, S., Coakes, E., Jack, G. (eds.): Beyond knowledge management. Idea Group Publishing, London (2004)

Loong, W.: Trust in e-commerce. Risk and trust building. In: Brennan, L.L., Johnson, V.E. (eds.) Computer-mediated relationships and trust. Managerial and organizational effects, pp. 176-193. Information Science Reference, Hershey (2008)

Lin, N.: Social capital: a theory of social structure and action. Cambridge University Press, Cambridge (2001)

Lundvall, B.: Innovation as an interactive process: from user-producer interaction to the national system of innovation. In: Dosi, G., Freeman, C., Silverberg, G., Soete, L. (eds.) Technical Change and Economic Theory. Pinter, London (1988)

Magalhães, R.: Organizational knowledge and technology. An action-oriented perspective on organization and information systems. Edward Elgar, Northampton (2004)

Mitchell, J.C.: Social Networks. Annual Review of Anthropology 3, 279-299 (1974)

Moitra, D., Krishnamoorthy, M.B.: Global innovation exchange. Res. Technol. Manag. 47(4), 32-38 (2004)

Nieto, M.J., Santamaría, L.: The importance of diverse collaborative networks for the novelty of product innovation. Technovation 27, 367-377 (2007), http: / /www.elsevier.com/ locate/technovation (accessed January 24, 2008)

Perkmann, M., Walsh, K.: University-industry relationships and open innovation: towards a research agenda. International Journal of Management Reviews 9(4), 259-280 (2007)

Perrons, R., Platts, K.: The role of clockspeed in outsourcing decisions for new technologies: insights from the prisoner's dilemma. Ind. Manag. + Data Sys. 104(7), 624-632 (2004)

Powell, W.W., Koput, K.W., Smith-Doerr, L.: Interorganizational collaboration and the locus of innovation: networks of learning in biotechnology. Adm. Sci. Q 41(1), 116-145 (1996)

Quinn, J.B.: Outsourcing innovation: The new engine of growth. Sloan Manag. Rev. 41(4), 13 $28(2000)$

Törrö, M.: Global intellectual capital brokering. In: Facilitating the emergence of innovations through network mediation, Espoo 2007. VTT Publications (2007)

von Hippel, E.: The Sources of Innovation. Oxford University Press, New York (1988)

Wellman, B.: Little boxes, glocalization, and networked individualism, Center for Urban \& Community Studies. University of Toronto (2002),

http: / /www. chass . utoronto. ca/ wellman/publications / [25-04-2008]

Yin, R.K.: Case study research. Design and methods, 3rd edn. Sage, Thousand Oaks (2003) 